University of Nebraska - Lincoln

DigitalCommons@University of Nebraska - Lincoln

Faculty Publications, Department of Psychology

Psychology, Department of

$1-1-1987$

\title{
Pubertal status and psychosocial development: Findings from the Early Adolescence Study
}

Lisa J. Crockett

University of Nebraska-Lincoln, ecrockett1@unl.edu

Anne C. Petersen

Pennsylvania State University, annepete@umich.edu

Follow this and additional works at: https://digitalcommons.unl.edu/psychfacpub

Part of the Psychiatry and Psychology Commons

Crockett, Lisa J. and Petersen, Anne C., "Pubertal status and psychosocial development: Findings from the Early Adolescence Study" (1987). Faculty Publications, Department of Psychology. 227.

https://digitalcommons.unl.edu/psychfacpub/227

This Article is brought to you for free and open access by the Psychology, Department of at DigitalCommons@University of Nebraska - Lincoln. It has been accepted for inclusion in Faculty Publications, Department of Psychology by an authorized administrator of DigitalCommons@University of Nebraska - Lincoln. 
Published in:

Biological-Psychosocial Interactions in Early Adolescence, edited by Richard M. Lerner and Terryl T. Foch. Lawrence Erlbaum Associates, Publishers. Hillsdale, New Jersey, 1987.

Copyright (c) 1987 by Lawrence Erlbaum Associates, Inc. Used by permission. 


\title{
Pubertal Status and Psychosocial Development: Findings from the Early Adolescence Study
}

\author{
Lisa J. Crockett \\ Anne C. Petersen \\ The Pennsy/vania State University
}

For decades, puberty has been assumed to be a major force affecting adolescent behavior. Psychoanalytic scholars have attributed some of the apparent changes in adolescent behavior to an increase in sexual drive (e.g., Blos, 1962; A. Freud, 1958; S. Freud, 1953) and, more recently, to the surge in gonadal hormones thought to underlie increases in libido (Kestenberg, 1967a, b, 1968). Puberty has been ascribed an important role in most aspects of adolescent life, from cognition (e.g., Carey, Diamond, \& Woods, 1980; Diamond, Carey, \& Back, 1983; Waber, 1977) to psychopathology (e.g., Kestenberg, 1967a, b, 1968; see also Petersen, 1985). Until quite recently, however, few researchers directly addressed the issue of pubertal effects on adolescent behavior-the assumption, though well accepted, remained largely untested.

In the last few years, several research groups have begun to investigate the effects of pubertal development empirically; our study is among this set of investigations. Beginning in 1978, we have conducted a longitudinal study of early adolescent development. A major objective of this research has been to examine the influence of pubertal changes on other aspects of development during this period. With regard to pubertal effects we wished to address two major questions. First, what aspects of behavior seem to be affected by pubertal development? (In other words, are pubertal effects pervasive or relatively circumscribed, and if they are circumscribed, which aspects of behavior are involved?) Second, how does pubertal change exert an influence-does it operate directly on specific aspects of behavior and performance (for example, via direct effects of pubertal hormones on the brain), or are pubertal effects more often indirect through the stimulus effects of somatic pubertal changes and mediated by psychological and social factors? Thus far, most of our efforts have been 
directed toward answering the first question; we have only recently begun to explore the second.

Our approach to the question of pubertal effects has involved considering two aspects of pubertal development: (1) level of pubertal maturation (pubertal status) at a particular point in time (in this case, a particular grade level in school); and (2) timing of puberty, that is, whether adolescents are early, on time, or late in their pubertal development relative to their peers. In the first case, we are able to detect differences in behavior that are a function of pubertal status, controlling for grade level in school. Moreover, by comparing the patterns of effects at one grade with those at another we can attempt to replicate findings. ${ }^{1}$ This procedure yields a fairly direct indication of which aspects of behavior are influenced by pubertal change and which of these effects are reliable. On the other hand, by comparing early, on time, and late developers on various indices of psychosocial development, we can explore the effects of being deviant in pubertal timing relative to one's peers. Previous research in this area (e.g., Clausen, 1975; Jones \& Bayley, 1950; Jones \& Mussen, 1958; Mussen \& Jones, 1957) suggests that deviance in this regard may be associated with lower self-image and related adjustment problems, particularly in the case of early-maturing girls and latematuring boys (the two groups that are most deviant in pubertal timing relative to the majority of peers).

Thus far we have examined pubertal status effects within grade with respect to a variety of constructs, including cognitive performance, school achievement, moods, relationships with parents, relationships with same-sex and other-sex peers, self-image, and satisfaction with one's appearance. Additional analyses comparing early, on time, and late maturers are reported elsewhere (Petersen \& Crockett, in press) and are only summarized here.

\section{METHOD}

\section{Design and Sample}

The Early Adolescence Study is a short-term longitudinal investigation of biological and psychosocial development in early adolescence (e.g., Petersen, 1984). Participants in the study were randomly selected from two suburban school districts in the Midwest. Two samples of sixth graders, representing successive birth cohorts, were drawn in consecutive years. These two cohorts were each followed from sixth through eighth grade within the framework of a cohort-

\footnotetext{
'It would be possible, however, for pubertal effects to interact with grade in school, resulting in effects that, although robust, appear only once or twice due to suppressor or moderating effects associated with grade. We would look closely, for example, at effects appearing at all but sixth grade in boys; most sixth-grade boys were prepubertal, thus reducing variance in pubertal status and reducing the likelihood of observing differences associated with pubertal status.
} 
sequential longitudinal design (Baltes, 1968; Schaie, 1965). Twice during each school year (fall and spring) individual interviews and group assessments were conducted with the participating students. Total sample size was 335 , but the data reported here are based on a subsample of 253 boys and girls who attended at least four interviews and four group assessment sessions. This subsample was identified for use in longitudinal analyses of our data.

\section{Measures}

Pubertal Development. The measure of pubertal development was a brief self-report instrument developed as part of the study. In the interview, adolescents were asked to rate the amount of change or development they had experienced with respect to several physical characteristics associated with pubertal maturation. These characteristics included body hair (pubic hair) growth, breast growth, skin changes, growth spurt, and menarche for girls; body hair growth, facial hair growth, skin changes, voice deepening, and growth spurt for boys. Ratings on each characteristic were made along a 4-point scale ranging from "1" = "no development" to " 4 " = "development completed." 2 Pubertal status scores were derived by summing the ratings made on the five characteristics appropriate to a given individual's gender and then dividing by five to retain the original metric from "1" to " 4 ." The Pubertal Development Scale has been found to be both reliable and valid (Petersen, Crockett, Richards, \& Boxer, 1984).

In addition to computing a pubertal status score, we were able to classify an individual's level of development in terms of five pubertal status categories: prepubertal, early pubertal, mid-pubertal, late pubertal, and postpubertal. Assignment to pubertal status categories was made separately for boys and girls. For girls, the assignment was made on the basis of reported level of breast development and body hair growth along with whether or not a girl reported having experienced menarche. For boys, the assignment was made on the basis of reported body hair growth, facial hair growth, and voice change. Boys' and girls' status classifications have been found to compare favorably with their pubertal status scores and hence appear to be valid (Petersen et al., 1984). Because we wanted to treat pubertal status as an independent variable, the status categories were used in the present analyses. The cell proportions for these categories are presented by grade, season, and gender in Table 8.1.

Self-image. Self-image (or self-concept) is thought to be a major indicator of adolescent personality change (e.g., Offer, 1969; Rosenberg, 1965). Self-

\footnotetext{
${ }^{2}$ Ratings of menarche (which is experienced as a discrete event) were dichotomous; reports of no menarche were scored as " 1 " = "no development" and reports of menarche as " 4 " = "development completed."
} 
TABLE 8.1

Frequency Distributions of Boys and Girls Across Pubertal Categories

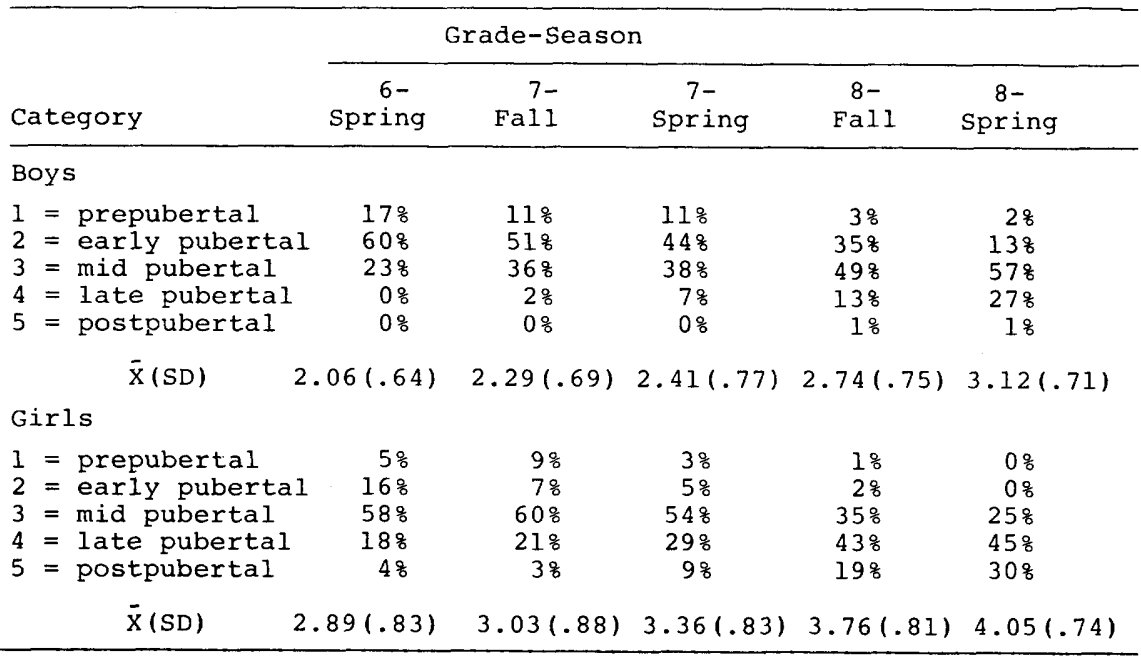

Note: Data for sixth-grade spring and seventh-grade fall are from Cohort II only $(\widehat{N=1} 13)$; otherwise, the two cohorts were pooled $(N=240)$.

image was assessed with the Self-Image Questionnaire for Young Adolescents (SIQYA; Petersen, Schulenberg, Abramowitz, Offer, \& Jarcho, 1984). Developed from the Offer Self-Image Questionnaire (Offer, Ostrov, \& Howard, 1982), the SIQYA is a 98-item self-report questionnaire that measures selfperceptions of one's functioning in nine important psychosocial domains. These domains include Impulse Control, Emotional Tone, Body-Image, Peer Relations, Family Relations, Coping, Vocational and Educational Goals, Psychopathology, and Superior Adjustment. Several of these subscales were used to measure constructs for the present set of analyses.

Satisfaction with One's Appearance. Because of the somatic changes associated with puberty, feelings about one's appearance are thought to be important during early adolescence (Clausen, 1975; Faust, 1983; Tobin-Richards, Boxer, \& Petersen, 1983). In the present analyses, satisfaction with one's appearance was assessed with the Body-Image subscale of the SIQYA and with interview questions concerning (1) perceptions of one's attractiveness, (2) satisfaction with one's height, weight, and timing of pubertal development relative to the peer group, and (3) the desire to change one's physical appearance.

Moods. Mood changes are often attributed to adolescents although there has been little previous research on mood changes in early adolescence (cf. Petersen \& Craighead, 1986). Moods were indexed using three of the SIQYA subscales: 
Impulse Control, Emotional Tone, and Psychopathology. In addition, two questions on the eighth-grade interview were used to measure this construct: " Do you have frequent mood changes that you cannot explain or control?" and "How often do you get upset or angry?"' Both of these questions were coded on a 5point scale ranging from "very rarely" to "very often."

Cross-sex Peer Relationships. One very influential hypothesis about puberty is that it enhances sex drive and stimulates interest in sexual relationships (Freud, 1953). Cross-sex relationships were assessed with several interview questions. In the interviews, adolescents were asked whether they talked to members of the other sex on the phone and whether they had a boyfriend or girlfriend. They were also asked to indicate how often they dated and (in eighth grade) how much they "made out." Responses to these latter two questions were coded on a 5-point scale.

Parent-Child Relationships. Previous research (Steinberg, 1981; Steinberg \& Hill, 1978) has shown that parent-child relationships change in conjunction with pubertal change. In the present analyses, parent-child relationships were assessed with the Family Relations subscale of the SIQYA and with several interview questions. In the interviews, adolescents were asked to rate the quality of their relationship with each parent (i.e., "How would you say things are going between you and your mother/father these days?'), the amount of arguing between them and their parents, and the amount of time the family spent doing things together. They also indicated whether or not they talked to their parents when they had problems.

Same-Sex Peer Relationships. Although there are no specific hypotheses linking puberty to changes in same-sex peer relations, links might be expected because of hypothesized changes in other-sex relations. For example, some researchers have reported that when adolescents become interested in the other sex, their relationships to same-sex friends may also intensify for a time (Douvan \& Adelson, 1966). In the present analyses, quality of same-sex peer relations was measured with the Peer Relations subscale of the SIQYA and with interview questions on which adolescents reported whether or not they (1) talked to friends when they had problems, (2) felt a friend understood them best, and (3) felt closest to a friend. Previous analyses have shown that the proportion of affirmative responses to all but the last of these questions increased in our sample over the junior high years (Crockett, Losoff, \& Petersen, 1984).

Cognitive Performance. Three aspects of cognitive performance were assessed: (1) mental rotations, a type of spatial ability, was measured by the Space subtest of the Primary Mental Abilities Test (Thurstone \& Thurstone, 1941); (2) field independence, a second type of spatial ability, was measured by the Group 
Embedded Figures Test (Witkin, Oltman, Raskin, \& Karp, 1971); and (3) fluent production, involving the rapid generation or manipulation of verbal material and symbols, was measured by the Clerical Speed and Accuracy subtest of the Differential Aptitude Test (Bennett, Seashore, \& Wesman, 1973). Formal operational thought or abstract reasoning (which is thought to represent a qualitative change in cognitive capacity, Inhelder \& Piaget, 1958) was assessed in terms of proportional reasoning using the Equilibrium in a Balance Test (Linn \& Pulos, 1980).

There have been several hypotheses linking pubertal status and pubertal timing to cognitive change (see Newcombe \& Dubas, this volume or Petersen, 1983 , for reviews). For example, Waber $(1976,1977)$ found that later maturers performed better than earlier maturers on tests of spatial ability. Carey and colleagues (e.g., Carey et al., 1980; Diamond et al., 1983) also found pubertal status effects with some cognitive measures.

School Achievement. As a measure of adjustment in the school setting, final grades in each of five subject areas - Literature, Language Arts, Math, Science, and Social Studies-were obtained from school records for the sixth, seventh, and eighth grades. Letter grades (including + and -) were translated into numerical scores using an 11-point scale ranging from " 0 " = " $\mathrm{F}$ " to " 11 " = "A." We hypothesized that puberty might have a disruptive effect on adjustment at school, resulting in a decline in grades.

\section{RESULTS}

A multivariate analysis of variance framework was used for examining pubertal status effects within grade levels. The inclusion of polynomial contrasts as part of the MANOVA procedure permitted assessment of linear and nonlinear trends across status categories (i.e., permitted identification of systematic changes associated with greater pubertal maturity).

\section{Effects of Pubertal Status}

The effects of pubertal status were isolated from those of grade level in school by performing separate polynomial contrast analyses at sixth, seventh, and eighth grade. Because girls are $1 \frac{1}{2}$ to 2 years ahead of boys in pubertal development, there was a possibility that pubertal status effects would be confounded with gender effects unless separate analyses were performed for the two sexes. Therefore, the MANOVAs were done separately for boys and girls. At each grade level, polynomial contrasts were performed on variables indexing satisfaction with one's appearance, moodiness, cross-sex relationships, same-sex relationships, parent-child relationships, cognitive performance, and course grades. Because some interview questions were not asked at all grade levels, the particu- 
lar variables included to measure some of these constructs varied from one grade to the next. The sets of variables used at each grade level appear in Table 8.2.

Table 8.3 provides a summary of the pattern of significant pubertal status effects for boys and girls. It is evident from the table that the significant effects (multivariate and univariate) tend to be concentrated in particular domains, notably satisfaction with one's appearance, other-sex relationships, moods, and relationships with parents. Occasionally, significant effects were found in other domains as well (e.g., same-sex relationships and cognitive performance), but because the multivariate effects were never significant and the particular univariate effects were not always replicated at other grade levels, these findings do not appear to be reliable. In our discussion we concentrate on those effects that show a multivariate effect and at least partial replication across grade levels, although some mention is made of nonreplicated effects.

Satisfaction with One's Appearance. Effects of pubertal status on feelings about one's appearance emerged in seventh and eighth grade for both boys and girls, although the multivariate effect was significant only for girls. For girls, only one appearance variable - satisfaction with one's weight- showed a significant effect of pubertal status. In both grades, the means indicated that more physically mature girls were generally less satisfied with their weight (although this trend was reversed in the postpubertal girls who reported slightly greater satisfaction with their weight than did late pubertal girls). For boys, different variables showed significant effects of pubertal status at the two grade levels. In seventh-grade boys (as in girls), pubertal status was significantly related to weight satisfaction. In contrast to the pattern for girls, however, boys with greater physical maturity tended to be more satisfied with their weight. In eighth grade, the only significant effect for boys was with wanting to change their appearance. Consistent with the findings at seventh grade, more mature boys reported less desire to change their appearance than did less mature boys.

Moods. Differences among pubertal status groups in terms of mood variables appeared only in seventh and eighth grade, and appeared more consistently in boys than in girls. The multivariate effect was significant only for boys in seventh grade. For boys at this grade level, significant linear effects of pubertal status were found for two variables: Impulse Control and Emotional Tone, two subscales of the SIQYA. In both cases, the means indicated a positive trend: Both Impulse Control and Emotional Tone were higher in pubertal than in prepubertal boys, with only minor variations across the early, mid, and late pubertal groups (in the form of a slight decline). This pattern was largely replicated at eighth grade with Emotional Tone.

For girls, an effect of pubertal status emerged only in eighth grade, and with only one variable: the reported frequency of becoming upset. The significant effect was quadratic, with late pubertal girls reporting a lesser tendency to 


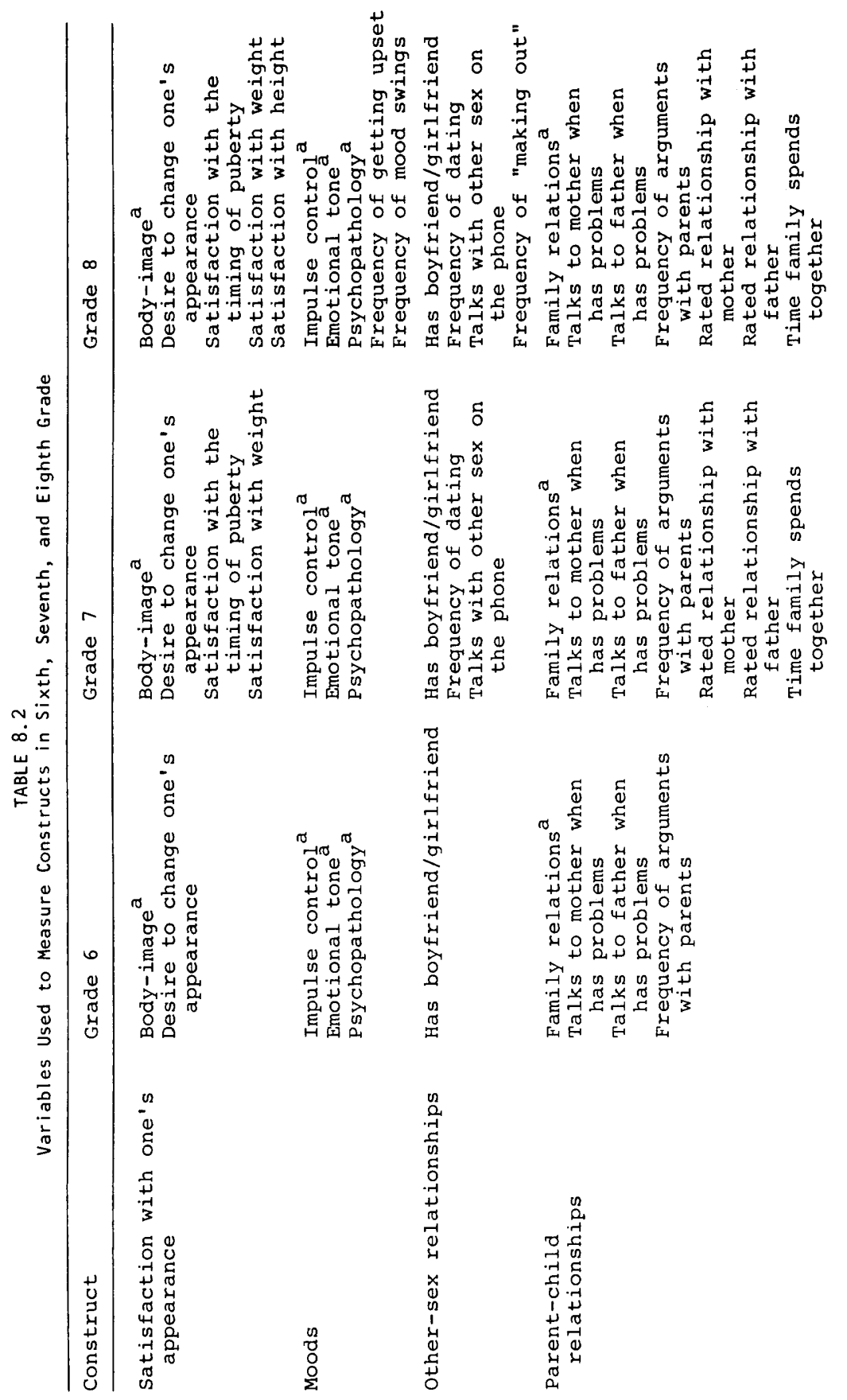



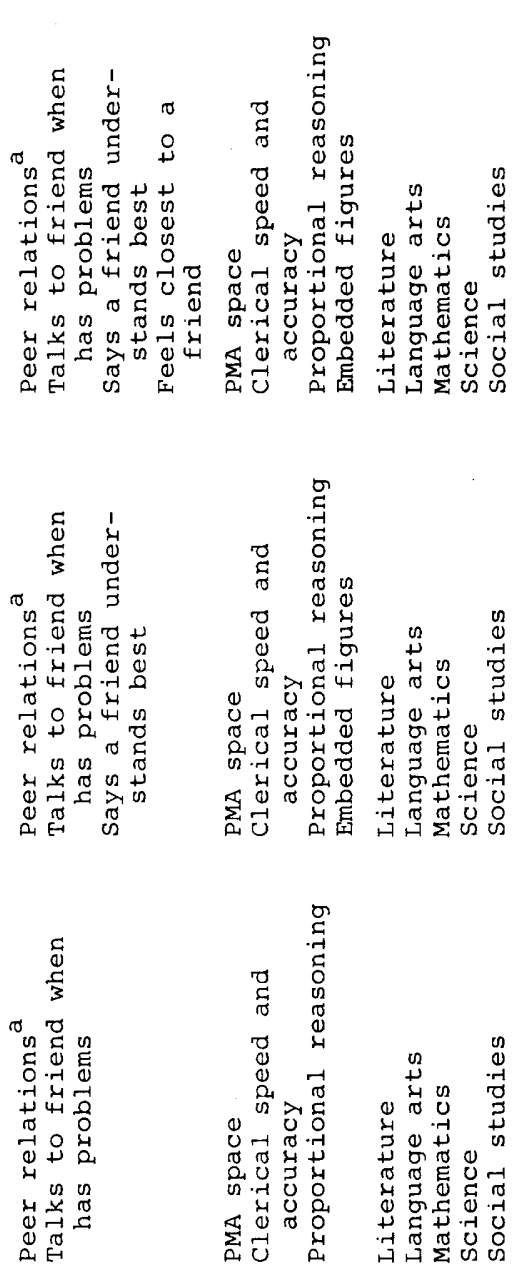

0
$0-1$
0
0
0
+1
0
0
0
0
$x$
0
0
0
0
0
0

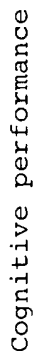

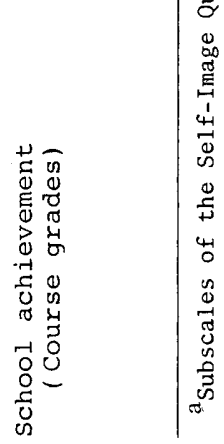


TABLE 8.3

Summary of Pubertal Status Effects by Gender and Grade-in-School

\begin{tabular}{|c|c|c|c|c|c|c|}
\hline \multirow[b]{2}{*}{ Construct } & \multicolumn{3}{|c|}{ Boys } & \multicolumn{3}{|c|}{ Girls } \\
\hline & 6 th & 7 th & 8 th & 6 th & $7 \mathrm{th}$ & 8 th \\
\hline Satisfaction with one's appea & NS & NS & NS & NS & * & * \\
\hline Moods & NS & & $\overline{\mathrm{NS}}$ & NS & NS & NS \\
\hline Cross-sex relationships & NS & NS & $\overline{\mathrm{NS}}$ & NS & $\underline{\text { NS }}$ & \\
\hline Parent-child relationships & NS & $\overline{\mathrm{NS}}$ & $\overline{\mathrm{NS}}$ & * & $\overline{\mathrm{NS}}$ & NS \\
\hline Same-sex relationships & NS & NS & NS & NS & NS & $\overline{\mathrm{NS}}$ \\
\hline Cognitive performance & NS & NS & $\overline{\mathrm{NS}}$ & NS & NS & NS \\
\hline School achievement & NS & NS & NS & $\widehat{\mathrm{NS}}$ & $\overline{\mathrm{NS}}$ & NS \\
\hline
\end{tabular}

Note: Significant multivariate effects are indicated by an asterisk (*); significant univariate effects in the absence of a significant multivariate effect are indicated by underscoring (i.e., NS).

become upset than either less mature or more mature girls; we chose to make little of this finding because it was not replicated, although others have reported higher order polynomial effects (e.g., Hill, this volume).

Cross-sex Relationships. The multivariate effect of pubertal status was signifiant in the case of relationships with the other sex, but only for girls in eighth grade. For girls in this grade, all four variables assessing other-sex relationships showed a significant effect of pubertal status: having a boyfriend, talking with boys on the phone, dating, and "making out." 3 In each case, more developed girls reported higher levels of heterosocial interaction. In seventh-grade girls, the multivariate effect was not significant, but a significant effect was found for talking with boys on the phone. Conforming to the general pattern found at eighth grade, more mature seventh-grade girls were more likely to report this activity than were less mature girls.

In boys, the multivariate effect was never significant with respect to cross-sex relationships, but significant univariate effects were found at both seventh and eighth grade. In seventh grade, talking with girls on the phone was significantly related to pubertal status; as was found in girls, more mature status was associated with a greater tendency to report this activity. In eighth grade, significant effects were found with "making out." Again, the general pattern was for more mature boys to report greater experience in this domain.

Parent-Child Relationships. Pubertal status effects on parent-child relationships appeared only for girls and, interestingly, at sixth grade and eighth grade but not at seventh. Moreover, the effects were found for different sets of variables at these two grade levels. The multivariate effect was significant in sixth grade 4 but not in eighth grade. In sixth grade, the reported tendency to talk

\footnotetext{
${ }^{3}$ In the case of dating, the univariate $p=.055$. The linear effect was significant $(p<.05)$, and the means indicated that the reported frequency of dating increased with pubertal status.

${ }^{4}$ For this latter variable ("making out"), the univariate $p=.055$.
} 
to parents about problems varied significantly by pubertal status: In general, the tendency to talk to mother declined in a linear fashion across pubertal status groups (after a slight peak in the early pubertal group); the tendency to talk to father showed a quadratic trend with a clear peak in the early pubertal group and a steady decline across the more mature groups. Finally, positive feelings about family relationships as measured by the Family Relations subscale of the SIQYA declined in a linear fashion across pubertal status groups, although the univariate effect did not reach significance.

In eighth grade, parent-daughter relationships also seemed to be affected by a girl's pubertal status. In this case, no univariate effects were significant, but significant linear patterns emerged with respect to the reported frequency of arguments with parents and the amount of time the family spent together. The frequency of arguing tended to increase with pubertal status, and time with the family tended to decrease, replicating the negative association between pubertal status and parent-daughter relationships found at sixth grade. It should also be mentioned that there was a nonsignificant upswing in reported quality of family relationships in the postpubertal eighth-grade girls: As a group, these groups reported less arguing and more time spent with the family than did late pubertal girls.

Same-Sex Relationships. An isolated univariate effect was found for samesex relationships among eighth-grade boys. The effect involved significant linear relationship such that more pubertally advanced boys generally showed a greater tendency to report feeling that a same-sex friend understood them best.

Cognitive Performance. Pubertal effects on cognitive performance were found for girls in both sixth and seventh grade, but the effects were found with entirely different types of abilities. In neither case was the multivariate effect significant. In sixth grade, a significant univariate effect was found for abstract reasoning scores. However, the effect was cubic and the means revealed no clear trends across status categories. Among seventh-grade girls, a significant effect was found with fluent production involving a significant linear increase in performance with greater pubertal status.

School Achievement. No significant effects were found with school achievement as measured by course grades. For the most part, course grades varied little across pubertal status categories.

\section{DISCUSSION}

The approach used in the analyses reported here was to examine pubertal status effects while controlling for grade-in-school. Differences across pubertal status categories were examined in seven domains, covering social relationships, cog- 
nitive and academic performance, moodiness, and feelings about one's appearance. To recapitulate, significant multivariate effects of pubertal status emerged in four domains: satisfaction with one's appearance, moods, other-sex relationships, and parent-child relationships. Isolated effects appeared for samesex relationships and cognitive performance. The nature (direction) of the changes related to pubertal status is detailed in Table 8.4.

At seventh and eighth grade, more mature girls tended to feel less satisfied with their weight but reported more heterosocial interaction in the form of having a boyfriend, dating, talking with boys on the phone, and "making out." At eighth grade, late pubertal girls reported a lesser tendency to become upset than did mid-pubertal or postpubertal girls. Finally, at sixth and eighth grades, greater physical maturity was associated with less positive parent-daughter relationships, in that more mature sixth-grade girls reported less positive family relationships and less willingness to talk to their parents about problems, whereas more mature eighth-grade girls reported somewhat more arguing with parents and somewhat less time spent with the family as a group. In sixth- and seventhgrade girls, some aspects of cognitive performance were also affected by pubertal status, although never consistently enough for the multivariate effect to be significant: Proportional reasoning scores showed a cubic relationship to pubertal status in sixth grade, whereas Clerical Speed and Accuracy performance was positively related to pubertal status in eighth.

In boys, effects of pubertal status were seen only after sixth grade, perhaps because most of the boys in this study did not reach puberty until seventh grade

TABLE 8.4

Direction of Change in Individual Variables with Increasing Pubertal Status

\begin{tabular}{|c|c|c|c|c|}
\hline \multirow[b]{2}{*}{ Construct/Variable } & \multicolumn{2}{|l|}{ Boys } & \multicolumn{2}{|l|}{ Girls } \\
\hline & Direction & (Grade) & Direction & (Grade) \\
\hline \multicolumn{5}{|l|}{ Appearance } \\
\hline Satisfaction with weight & increase & e (7) & decrease & $(7,8)$ \\
\hline $\begin{array}{l}\text { Desire to change } \\
\text { Moods }\end{array}$ & \multicolumn{3}{|c|}{ Moods } & \\
\hline Impulse control & increase & e (7) & & \\
\hline Emotional tone & increase & e $(7,8)$ & & \\
\hline How often upset & & & mixed (8) & \\
\hline \multicolumn{5}{|l|}{ Other-Sex Relationships } \\
\hline Talks on phone & increase & e (7) & increase & $(7,8)$ \\
\hline Boyfriend/girlfriend & & & increase & (8) \\
\hline Dating & & & increase & (8) \\
\hline Making out & increase & e (8) & increase & (8) \\
\hline \multirow{2}{*}{\multicolumn{5}{|c|}{$\begin{array}{l}\text { Parent-Child Relationships } \\
\text { Talks about problems: }\end{array}$}} \\
\hline & & & & \\
\hline to mother & & & decrease & (6) \\
\hline to father & & & mixed (6) & \\
\hline Family relations & & & decrease & (6) \\
\hline Arguments & & & increase & (8) \\
\hline Time family spends together & & & decrease & (8) \\
\hline \multicolumn{5}{|l|}{ Same-Sex Relationships } \\
\hline Says a friend understands best & increase & e (8) & & \\
\hline \multicolumn{5}{|l|}{ Cognitive Performance } \\
\hline Proportional reasoning & & & mixed (6) & \\
\hline Fluent production & & & increase & (7) \\
\hline
\end{tabular}


or later (Petersen et al., 1984). Boys' satisfaction with their appearance was affected by pubertal status in seventh and eighth grade, although different aspects of appearance were involved and the multivariate effect was never significant. Overall, greater maturity was associated with greater satisfaction with one's appearance: More mature boys were somewhat more satisfied with their weight in seventh grade and were less likely to want to change their appearance in eighth. In seventh and eighth grade, other-sex relationships were also affected (although the multivariate affects were not significant): Greater physical maturity was associated with a greater tendency to report talking to girls on the phone in seventh grade and with more frequent "making out" in eighth. Moreover, in seventh and eighth grade, boys' moods were affected, with Emotional Tone and Impulse Control increasing with pubertal status in seventh grade, and Emotional Tone increasing with pubertal status in eighth. Finally, an isolated effect was found with same-sex relationships in eighth-grade boys: More mature boys were more likely to report that a same-sex friend understood them best.

The pattern of findings regarding pubertal status effects within grade level demonstrates two things. First, pubertal status effects, rather than being pervasive, are concentrated in a few domains of early adolescent life: moods, othersex relationships, and satisfaction with one's appearance. (There is also some indication that the parent-child relationships is affected in girls.) Not surprisingly, these three areas are those most obviously related to pubertal change: Pubertal change produces changes in appearance (to which boys and girls seem to respond differently); the changes in appearance are associated with an increase in othersex interaction (because a more adult physique is attractive to the other sex or because hormone changes underlying the somatic changes lead to an increased interest in the other sex, or both); and, finally, the hormonal changes and the accompanying physical changes may directly affect mood state.

Many of the particular findings for boys and girls are consistent with those of other researchers. Specifically, our finding that greater pubertal maturity was related to lesser satisfaction with one's appearance in girls (specifically with respect to weight) but to greater satisfaction in boys echoes findings from other studies that suggest that physical maturation tends to be a positive experience for boys but may be perceived negatively by girls (e.g., Simmons, Blyth, \& McKinney, 1983). Moreover, the finding that, for both sexes, greater physical maturity was associated with increased heterosocial interaction is consistent with the hypothesized increase in libido (Freud, 1953), although it is also consistent with the possibility that more mature adolescents are viewed as more attractive by members of the other sex.

Closer inspection of the specific pubertal status effects suggests a second general point: Pubertal effects are frequently not so strong that they consistently influence whole sets of indicators, but rather, one indicator at one grade level and another indicator at the next may be involved. This was the case with parentchild relationships and cognition in girls, and with other-sex interaction, samesex relationships, and satisfaction with appearance in boys. The lack of con- 
sistency suggests that the effects of pubertal status may be weak and variable.

Other analyses examining the effects of pubertal maturation in this sample tend to support the conclusion that pubertal effects are relatively weak and circumscribed. Repeated measures analyses of pubertal timing effects on adjustment have revealed that effects of pubertal timing were confined to course grades and some of the self-image scales. This pattern was in contrast to "grade-inschool," which was related to significant effects for nearly every aspect of adjustment measured (Petersen \& Crockett, 1985).

Analyses examining the effects of pubertal maturation on sex-role development and perceptions of self have also been performed using this data set (McNeill, 1984). As in the analyses reported here, few consistent relationships between pubertal status and sex-role indicators emerged, beyond the finding that more physically developed girls were less satisfied with their weight. One additional relationship emerged between pubertal development and positive attitudes towards athletics in girls. For boys, only one relationship was found between overall pubertal level and a psychosocial variable; the association suggested that more developed boys reported spending more time with a good friend than did less developed boys. (This is consistent with our finding that more mature boys were more likely to feel a friend understood them best.) Although these few findings appear to be robust, it is clear that pubertal status affects fewer aspects of early adolescent development than might be expected. This general conclusion is in agreement with the conclusions of other researchers who report that pubertal effects are specific rather than global (Simmons et al., 1983).

The nature of particular pubertal effects will be clarified by analyses addressing the additional question of whether the effects of pubertal development on adolescent behavior are direct physical (e.g., hormonal) effects or effects mediated by social and psychological responses to pubertal changes. Richards (1984) is currently examining specific relationships between pubertal maturation and body-image. A number of social and psychological variables may modulate this relationship, including young people's perceptions of whether the timing of their pubertal development is early, on time, or late, relative to peers and their perceptions of friendship and peer relationships. LISREL is being used to determine whether a direct effects model or a complex, mediated effects model provides a better fit to the data. Analyses to date indicate that the mediated effects model provides a better fit (Richards, 1984).

Other hypotheses for integrating these and other new findings on pubertal effects were described by Petersen earlier in this volume. It is quite clear at this point that attributions of pervasive influence to puberty are inappropriate. It also appears likely that for most phenomena pubertal effects, where they exist at all, are mediated by other factors. Which other factors and the processes through which these factors have influence remain interesting and important questions for future research. 


\section{ACKNOWLEDGMENTS}

The research reported here was supported by Grant MH 30252/38142 to A. Petersen. We gratefully acknowledge the work of the the entire staff of the Early Adolescence Study, as well as the contributions of the young adolescents who participated in the research.

\section{REFERENCES}

Baltes, P. B. (1968). Longitudinal and cross-sectional sequences in the study of age and generation effects. Human Development, $11,145-171$.

Bennett, G. K., Seashore, A. G., \& Wesman, A. G. (1973). The Differential Aptitude Test. New York: The Psychological Corporation.

Blos, P. (1962). On adolescence: A psychoanalytic interpretation. New York: Free Press.

Carey, S. E., Diamond, R., \& Woods, B. (1980). Development of face recognition-A maturational component? Developmental Psychology, 16, 257-269.

Clausen, J. A. (1975). The social meaning of differential physical and sexual maturation. In S. E. Dragastin \& G. H. Elder (Eds.), Adolescence in the life cycle: Psychological change and social context (pp. 25-47). New York: Wiley.

Crockett, L. J., Losoff, M., \& Petersen, A. C. (1984). Perceptions of the peer group and friendship in early adolescence. Journal of Early Adolescence, 4, 155-181.

Diamond, R., Carey, S., \& Back, K. J. (1983). Genetic influences on the development of spatial skills during early adolescence. Cognition, 13, 167-185.

Douvan, E., \& Adelson, J. (1966). The adolescent experience. New York: Wiley.

Faust, M. S. (1983). Alternative constructions of adolescent growth. In J. Brooks-Gunn \& A. C. Petersen (Eds.), Girls at puberty: Biological and psychosocial perspectives (pp. 105-125). New York: Plenum Press.

Freud, A. (1958). Adolescence: Psychoanalytic study of the child (Vol. 13). New York: International Universities Press.

Freud, S. (1953). A general introduction to psychoanalysis (Joan Riviere, Trans.). New York: Permabooks. (Originally published, 1905)

Inhelder, B., \& Piaget, J. (1958). The growth of logical thinking from childhood to adolescence. New York: Basic Books.

Jones, M. C., \& Bayley, N. (1950). Physical maturing among boys as related to behavior. Journal of Educational Psychology, 41, 129-148.

Jones, M. C., \& Mussen, P. H. (1958). Self-conceptions, motivations, and interpersonal attitudes of early- and late-maturing girls. Child Development, 29, 491-501.

Kestenberg, J. (1967a). Phases of adolescence with suggestions for a correlation of psychic and hormonal organizations: Antecedents of adolescent organizations in childhood. Part I. Journal of the American Academy of Child Psychiatry, 6, 427-463.

Kestenberg, J. (1967b). Phases of adolescence with suggestions for a correlation of psychic and hormonal organizations: Antecedents of adolescent organizations in childhood. Part II. Journal of the American Academy of Child Psychiatry, 6, 577-614.

Kestenberg, J. (1968). Phases of adolescence with suggestions for a correlation of psychic and hormonal organizations. Part III. Puberty, growth, differentiation, and consolidation. Journal of the American Academy of Child Psychology, 7, 108-151.

Linn, M. C., \& Pulos, S. (1980). Proportional reasoning during adolescence: The Balance Puzzle. (Adolescent Reasoning Project, Rep. No. 25.) Berkeley: University of California, Lawrence Hall of Science. 
McNeill, S. (1984). Development of sex role perceptions during early adolescence. Unpublished doctoral dissertation, University of Chicago.

Mussen, P. H., \& Jones, M. C. (1957). Self-conceptions, motivations, and interpersonal attitudes of late- and early-maturing boys. Child Development, 28, 243-256.

Offer, D. (1969). The psychological world of the teenager. New York: Basic Books.

Offer, D., Ostrov, E., \& Howard, K. I. (1982). The Offer Self-Image Questionnaire for Adolescents: A manual (3rd ed.). Michael Reese Hospital, Chicago.

Petersen, A. C. (1983). Pubertal change and cognition. In J. Brooks-Gunn \& A. C. Petersen (Eds.), Girls at puberty: Biological and psychosocial perspectives (pp. 179-198). New York: Plenum Press.

Petersen, A. C. (1984). The Early Adolescence Study: An overview. Journal of Early Adolescence, 4, $1-4$

Petersen, A. C. (1985). Pubertal development as a cause of disturbance: Myths and realities. Genetic, Social, and General Psychology Monographs, 111, 205-232.

Petersen, A. C., \& Craighead, W. E. (1986). Emotional and personality development in normal adolescents and young adults. In G. Klerman (Ed.), Suicide and depression among adolescents and young adults (pp. 19-52). New York: Guilford Press.

Petersen, A. C., \& Crockett, L. J. (1985). Pubertal timing and grade effects on adjustment. Journal of Youth and Adolescence, 14, 191-206.

Petersen, A. C., Crockett, L. J., Richards, M. H., \& Boxer, A. M. (1984). Measuring pubertal development: Reliability and validity of a self-report measure. Manuscript submitted for publication.

Petersen, A. C., Schulenberg, J. E., Abramowitz, R. H., Offer, D., \& Jarcho, H. (1984). A SelfImage Questionnaire for Young Adolescents (SIQYA): Reliability and validity studies. Journal of Youth and Adolescence, 13, 93-111.

Richards, M. H. (1984). Effects of puberty on perceptions of self: The impact of gender-related developmental differences. Unpublished doctoral dissertation, University of Chicago.

Rosenberg, M. (1965). Society and the adolescent self-image. Princeton: Princeton University Press.

Schaie, K. W. (1965). A general model for the study of developmental patterns. Psychological Bulletin, 64, 92-107.

Simmons, R. G., Blyth, D. A., \& McKinney, K. L. (1983). The social psychological effects of puberty on white females. In J. Brooks-Gunn \& A. C. Petersen (Eds.), Girls at puberty: Biological and psychosocial perspectives (pp. 229-272). New York: Plenum Press.

Steinberg, L. D. (1981). Transformations in family relations at puberty. Developmental Psychology, 17, 833-840.

Steinberg, L. D., \& Hill, J. P. (1978). Patterns of family interaction as a function of age, the onset of puberty, and formal thinking. Developmental Psychology, 14, 683-684.

Thurstone, L. L., \& Thurstone, T. G. (1941). The Primary Mental Abilities Tests. Chicago: Science Research Associates.

Tobin-Richards, M. H., Boxer, A. M., \& Petersen, A. C. (1983). The psychological significance of pubertal change: Sex differences in perceptions of self during early adolescence. In J. BrooksGunn \& A. C. Petersen (Eds.), Girls at puberty: Biological and psychosocial perspectives (pp. 127-154). New York: Plenum Press.

Waber, D. P. (1976). Sex differences in cognition: A function of maturation rate? Science, 192, 572-574.

Waber, D. P. (1977). Sex differences in mental abilities, hemispheric lateralization, and rate of physical growth at adolescence. Developmental Psychology, 13, 29-38.

Witkin, H. A., Oltman, P. K., Raskin, E., \& Karp, S. A. (1971). Manual for the Group Embedded Figures Test. Palo Alto, CA: Consulting Psychologists Press. 